Shpengler, O. (1998). Zakat Evropy : in 2 vols. Vol. 1. Geshtal't i deistvitel'nost'. Moscow, Mysl'. 663 p. (In Russ.).

Shtompka, P. (1996) Sotsiologiia sotsial'nykb izmenenii / transl. from English; ed. by V. A. Iadov. Moscow, Aspekt-press. 414 p. (In Russ.).

Global culture: Nationalism, globalization a. modernity (1990) A theory, culture \& society spec. iss. / ed. by M. Featherstone. London etc, Sage. 411 p.

Meadows, D. H., Randers, J., Meadows, D. L., Behrens, W. W. (1972) The Limits to Growth: A Report for the Club of Rome's Project on the Predicament of Mankind. New York, Universe Books. 205 p.

Ritzer, G. (2000) Modern Sociological Theory. $5^{\text {th }}$ edition. Boston, McGraw-Hill. 435 p.

Robertson, R., Khondker, H. (1998) Discourses of globalization: preliminary considerations. International Sociology, vol. 13, no. 1, pp. 25-40.

Schwab, K., Malleret, T. (2020) COVID-19: The Great Reset. Forum Publishing, 280 p. $216 \mathrm{p}$.

Smith, Anthony D. (1995) Nations and Nationalism in a Global Era. Cambridge, Polity Press.

Waters, M. (1995) Globalization. Key ideas. London, Routledge. 185 p.

Weizsäcker, E. von, Wijkman, A. (2018) Come On! Capitalism, Short-termism, Population and the Destruction of the Planet. A Report to the Club of Rome by Ernst von Weizsäcker and Anders Wijkman, co-authors in cooperation with 34 more Members of the Club of Rome prepared for the Club of Rome's 50th Anniversary in 2018. Springer Science+Business Media LLC. $220 \mathrm{p}$.

Submission date: 14.08 .2021$.

Костина Анна Владимировна - доктор философских наук, доктор культурологии, профессор, проректор по научной работе Московского гуманитарного университета, академик Международной академии наук (Инсбрук, Австрия). Адрес: 111395, Россия, г. Москва, ул. Юности, д. 5. Тел.: +7 (499) 374-75-95. Эл. адрес: Anna_Kostina@inbox.ru

Kostina Anna Vladimirovna, Doctor of Philosophy, Doctor of Culturology, Professor, ViceRector for Research, Moscow University for the Humanities; Member, International Academy of Sciences (Innsbruck, Austria). Postal address: 5, Yunosti St., Moscow, Russian Federation, 111395. Tel.: +7 (499) 374-75-95. E-mail: Anna_Kostina@inbox.ru

DOI: $10.17805 /$ zpu.2021.4.9

\title{
Пандемия COVID-19 в 2021 году: проблемы доверия
}

\author{
В. Г. ФЕДОТОВА \\ ИНСТИТУТ ФИЛОСОФИИ РАН
}

В статье рассмотрено влияние пандемии коронавируса на повседневность. Автор обращается к социальной феноменологии А. Щюца и его концепции дома. Изменившись под влиянием пандемии и ее ограничений, дом бросает вызов нашим представлениям о нем. Он начинает выглядеть как чей-то чужой дом, мы становимся для него чужаками. Изменения дома ставят нас в позицию людей, лишенных части субъектности. 
Пандемия застает многие общества в кризисе доверия институтам, который проявлял себя задолго до ее прихода. Показаны области доверия, наиболее подверженные эрозии в условиях пандемии. Доверие перераспределяется: оно редуцируется с уровня макроструктур к микросоциальным взаимодействиям. Одним из проявлений проблемы доверия стало нежелание людей многих стран мира вакцинироваться. Мотивация, лежащая в основе нежелания и откладывания вакцинирования, содержит как универсально используемые оправдания, так и некоторые аргументы, отражающие российскую специфику.

Взаимность или реципрокность представляет собой направленность действия человека по отношению к другим людям или социальным структурам и проявляется, в частности, в отношении людей к новым практикам использования масок и вакцинации. Проблема доверия и взаимности находит отражение в коллективной ответственности - готовности защитить других от инфекции с помощью ношения масок и собственной вакцинации. Уровень коллективной ответственности во многих странах не является высоким.

В связи с кризисом доверия люди испытывают неудовлетворенную потребность доверять. Решение проблемы доверия автор видит в необходимости его социального конструирования с помощью политики доверия.

Ключевые слова: коронавирус; пандемия; эпидемиологический переход; дом; доверие; кризис доверия; ношение масок; вакцинация; взаимность

\section{ВВЕАЕНИЕ}

Сциально-философские дискуссии 2020 г. по проблематике влияния пандемии коронавируса на общество были связаны с обсуждением новых норм - регулирования пандемии с помощью введения мер локдауна, социального дистанцирования, минимизации социальных контактов, изоляции и пр. Особое внимание в работах прошлого года отводилось опасности левиафанизации государства, гипертрофии власти, нормализации раздувания государственных полномочий как во время пандемии, так и после нее в условиях снижения противовесов в виде гражданского общества, а также ущемления прав человека в пользу соображений коллективной безопасности. Из 2020 г. казалось, что пандемия ослабится в нынешнем году. Автор данной статьи опубликовала в прошлом году работы о жизни в условиях коронавируса (см., напр.: Федотова, 2020), предполагая, как и многие, что наступающий год станет переломным в плане остановки эпидемии, и что, как результат, эта проблема будет терять свою научную и практическую актуальность. Эти ожидания пока еще достаточно далеки от воплощения в реальность, а эпидемия порождает новые вызовы. В 2021 г. произошли изменения языка и направлений дискуссии. К примеру, одним из ярких изменений стал отход от использования понятия «новой нормальности». Самые обсуждаемые вопросы текущего года связаны с обращением к проблемам доверия, которые в меньшей степени присутствовали в дискурсе социальных наук 2020 г.

\section{ЭПИАЕМИОАОГИЧЕСКИЙ ПЕРЕХОА}

Мы уже однажды отметили, что причиной неготовности как ученых, так и властных институтов и простых людей к пандемии коронавируса стал так называемый эпидемиологический переход, осуществленный в середине ХХ в. Поясним чуть более подробно. Эпидемиологический переход изменил режимы заболеваемости и смертности населения. Его суть состояла в том, что причины заболевания и смерти перестали быть инфекционными по своей природе (такими, как чума, оспа, полиомиелит, туберкулез и пр.), в прежние времена являвшимися наиболее распространенными. В 1960-е гг. эти болезни перестали быть массовыми ввиду изобретения 
вакцин от основных известных возбудителей инфекций и проведения кампаний по вакцинации своих граждан странами с развитыми системами здравоохранения. Причины смертности в этих странах сместились в сторону сердечно-сосудистых заболеваний, рака, диабета и пр., т. е., по сути, смерти от болезней, связанных с возрастающей продолжительностью жизни. Аля подобного типа болезней весьма значимы поведенческие факторы, образ жизни и контроль за собственным здоровьем. Отметим, что, несмотря на то что СССР осуществил эпидемический переход, победив инфекционные эпидемии в то же самое время, что и западные страны, у страны не хватило политической воли и ресурсов на перестраивание здравоохранения для ответа на новые вызовы. То есть, осуществив первую часть перехода (изгнав инфекционные эпидемии), он не перешел к осуществлению его второй стороны.

В связи с пройденным эпидемиологическим переходом переживание эпидемий, равно как и память об успехах вакцинаций, исчезли из опыта благополучных в плане здравоохранения стран. Аостаточно долгий период жизни без масштабных эпидемий на протяжении около полувека сформировал как у людей, так и властных институтов представления о том, что подобные эпидемии - в прошлом или, по меньшей мере, являются локальными и контролируемыми, происходят в бедных странах со слабой медициной и не способны выйти за их пределы. Такое представление сложилось в массовом понимании, в частности, об эпидемии эболы, которая воспринимается как локально сдерживаемая и поэтому далекая от нас угроза. ВИЧ-инфекция, обнаруженная в начале 1980-х годов, казалась исключением, а не эпидемией, касающейся каждого, а также скорее (хотя это и оказалось позднее не соответствующим действительности) данью рисковому поведению и образу жизни тех, кто был ею охвачен, что стигматизировало ее носителей. Подобный перенос фокуса на индивидуальное поведение заразившихся снимал с этой эпидемии статус массовой и неизбежной, в связи с чем в целом благополучность постэпидемического контекста жизни не ставилась под сомнение. Новые инфекции начала XXI в. - птичий и свиной грипп - были восприняты как редкое и исключительное отклонение от магистральной тенденции постэпидемического настоящего. Типизация угроз и опасностей для здоровья, осуществляемая как на уровне здравого смысла, так и на уровне управленческих и организационных решений, перестала включать эпидемии в качестве потенциальных будущих угроз. Итогом многолетнего везения в плане отсутствия эпидемий инфекционных заболеваний, передающихся воздушным путем, стало то, что государства, системы здравоохранения и сами люди в XXI в. оказались не готовы к их возвращению. Одним из следствий такого определения ситуации стало не только недофинансирование систем здравоохранения, но и отсутствие резерва средств защиты (в первую очередь масок) и приборов $И В \Lambda$, а также предприятий, готовых их произвести в сжатые сроки. Возвращение эпидемий в жизнь современного общества спровоцировало как появление разрывов с привычной повседневностью, так и усиление кризисных явлений в области доверия.

\section{ЭПИАЕМИИ И АОМ}

Аля характеристики изменений, происходящих в повседневной жизни человека в условиях пандемии, обратимся к социальной феноменологии А. Щюца и к введенному им понятию «дом», под которым Щюц понимает «нулевую точку системы 
координат, которую мы приписываем миру, чтобы найти свое место в нем» (Щюц, 2004: 551). Щюц показал, что дом - это «особый способ жизни, составленный из маленьких и привычных элементов, которые нам дороги» (там же). Согласно Щюцу, «чувствовать себя как дома» означает высшую степень близости и интимности, достигаемую за счет следования рутинным образцам, к которым относятся традиции, привычки, институты, распорядок разных видов деятельности. Сегодня, несмотря на рост значимости цифрового пространства, опосредствованного новыми технологиями, жизнь дома подразумевает значительное число живых взаимодействий. Основным свойством дома является привычность и нормальность подобного образа жизни. Вторжение эпидемий и ограничительных мер, связанных с ними, прерывает привычность.

А. Щюц описывал ситуацию человека, который вынужден покинуть дом и должен в связи с этим приспосабливаться, оказавшись в ином пространстве, которое «не покрывается системой координат, используемых как схема референции у себя дома» (там же: 553). В условиях эпидемии коронавируса менялись не мы, покидая дом, а сам дом, в связи с чем каждый человек «не испытывает в опыте живого настоящего многих социальных отношений, составляющих текстуру его домашней группы, в качестве их участника» (там же).

Одной из ярких характеристик пандемической повседневности стало увеличение экранного времени, т. е. времени, проводимого у экрана современных электронных устройств. Рассмотрим разрыв с привычной формой физического разговора. Исследователи Стэнфордского университета выявили следующие причины, приводящие к неудовлетворенности общением и усталости от него во время использования сервисов видеозвонков и видеоконференций, заменивших физическое взаимодействие (Bailenson, 2021). Во-первых, во время видеосвязи увеличивается время контакта глаза в глаза с другим человеком в отличие от повседневного общения вне виртуальной реальности, когда мы только часть времени смотрим в глаза собеседнику, периодически отводя взгляд и переводя его на другие предметы. Кроме того, лица собеседников на экране находятся ближе и выглядят больше, чем в обычной жизни, что вызывает стресс от ощущения вторжения другого человека в нашу интимную зону, которую принято оберегать от посторонних. Во-вторых, человек устает от того, что он сам видит себя на экране (как в зеркале) во время общения. Такой опыт не является для нас привычным и нормальным. Третьей причиной становится то, что приходится застывать в одной позе, не имея возможности изменить положение, чтобы не выйти за пределы угла обзора камеры. Наконец, в-четвертых, в отличие от взаимодействия лицом к лицу, мы лишены возможности считывать невербальные сигналы. Поэтому, отмечают авторы исследования, если человек хочет показать другому, что он с ним согласен, ему приходится преувеличенно кивать головой и пр. Когнитивная нагрузка при таком общении возрастает в связи с тем, что нам приходится тратить больше сил «для отправки и приема сигнала» (там же). Социальное взаимодействие в таком формате требует больших усилий от его участников, делает его непривьчно интенсивньм, требуюшим большей вовлеченности.

Повседневность, в которой мы живем в условиях пандемии, являет собой необычный социальный конструкт. Она содержит в себе многое из того, что является домом и не изменилось во время пандемии. Однако она также содержит элементы нового, которые комбинируются с привычными практиками. Таким образом, дом 
любого человека являет собой некоторый гибрид прежнего дома и новаций, что приводит к особому опыту его восприятия как «дом и в то же время не-дом». Мы сегодня живем одновременно и дома, и не дома. Мы тяжело воспринимаем подобную амбивалентность, которая идет вразрез с представлением о моем доме, добавляя ему чуждости. А. Шюц отмечал, что «в определенной мере каждый возвращающийся домой вкушает магические плоды отстраненности, будь они сладки или горьки» (Щюц, 2004: 555). Отличие нашей ситуации заключается в том, что, хотя мы сами никуда не уходили из дома, исключительно быстро и радикально изменившийся контекст домашней жизни в условиях пандемии приводит к схожим результатам. Мы испытываем отстраненность и отчужденность. Наш дом начинает bblглядеть как чей-то чужой дом, мь становимся для него чужаками. Наш дом поменялся, нал некуда вернуться. Новый статус чужака метафорически можно выразить через сопоставление ситуации гражданина и человека, имеющего разрешение на жительство. Гражданин - это состояние устойчивости, наиболее полное статусное воплощение, в отличие от негражданства - которое по определению ограничено в своих возможностях. Изменения дома ставят нас в позицию неграждан, лишенных части субьектности.

\section{КРИЗИС АОВЕРИЯ КАК КОНТЕКСТ}

Начиная с 1990-х гг. в дискурсе социальных наук произошел рост интереса к изучению доверия и его роли в социальных отношениях. Аоверие характеризуется как ресурс, находящийся в распоряжении как индивидуальных, так и коллективных акторов. По мнению многих исследователей, его нехватка равносильна дополнительному налогу, накладываемому на взаимодействия, общество в целом и сферы его функционирования. Известный польский социолог П. Штомпка обобщил совокупность причин, которые обусловили подъем значимости данной проблематики (Штомпка, 2012). Эти причины помещают доверие в более широкий социокультурный контекст жизни в современных обществах. Приведем некоторые из них:

- «Мы перешли от обществ, опирающихся на судьбу, к обществам, опирающимся на человеческую субъективность» (там же: 55), отмечает он. Целенаправленные действия людей в большей степени влияют на мир сегодня, а для того, чтобы спланировать будущее, нам нужно оказывать доверие политическим, техническим, образовательным и прочим системам.

- Социальная жизнь содержит значительное число новых угроз и опасностей, причиной возникновения которых стали мы сами: «...наша деятельность неожиданно обратилась против нас самих» (там же: 56). Технические достижения предоставляют нам как определенные преимущества, так и создают возможности для катастроф, разрушения окружающей среды, болезней, вызванных цивилизацией. Преодоление явлений общества риска требует обращения к ресурсам доверия.

- Особенностью современного мира становится значительный объем возможностей, вариантов выбора действия (в области потребления, досуга, образования, здоровья и т. А.), находящихся как в моем распоряжении, так и в распоряжении других. Чем больше таких возможностей, тем менее предсказуемы принимаемые решения. Чтобы выбрать среди этих вариантов, надо прибегать к доверию. 
- Технические, организационные и институциональные системы, а также их глобальное функционирование становятся слишком сложными и «непрозрачными» даже для экспертов. Однако реализация наших потребностей и интересов требует доверия в отношении этих систем (там же: 55-58).

Приведенный список причин не является исчерпывающим, но намечает контуры сложного общества. Если исходные интенции доверять сталкиваются с действиями другой стороны, которые воспринимаются как действия, не направленные на удовлетворение наших интересов и потребностей, выбор может осуществляться в пользу недоверия. Недоверие, согласно мнению П. Штомпки, связано с ожиданиями действий других против моих интересов, является негативным залогом, который принимается на будущее поведение людей (там же: 83). Частый выбор недоверия как основы действия порождает среду недоверия, в которой большую роль могут играть слухи, искаженная информация и неформальные практики.

Несмотря на значимость поддержания определенного уровня доверия для успешного функционирования социальной жизни, уже в последние десятилетия $\mathrm{XX}$ в. был отмечен нарастающий кризис доверия - снижение доверия к основным социальным институтам, к числу которых можно отнести правительства, науку, здравоохранение и пр. Падение доверия к власти и вообще к экспертам - не новое явление. По мнению некоторых исследователей, оно впервые проявилось после поражения США во вьетнамской войне, усилилось после чернобыльской аварии и в результате уменьшения чувства безопасности после начала глобализации.

Изучением состояния общественного доверия занимаются сегодня не только исследователи, но и консалтинговые компании. Американская консалтинговая компания Edelman более 20 лет назад запустила собственный проект - «Барометр доверия». Ее доклад в 2020 г. свидетельствовал о вкладе неравенства доходов в проблему доверия. В развитых экономиках, согласно авторам доклада, доверие оторвалось от роста ВВП, люди не считают, что им достается справедливая доля благополучия. В результате происходит падение доверия таким институтам, как правительство, бизнес, неправительственные организации и медиа. Аоверие людей является результирующей оценки двух различных факторов, которые принимаются в расчет: компетентность и этичность поведения (Edelman Trust Barometer, 2020: Электронный ресурс).

Сниженное доверие, как показывает известный специалист по проблемам знания Н. Штер, порождает сопротивление политике, которую проводят властные структуры: «...утрата последними власти проявилась в первую очередь в форме нерешения, что означает не что иное, как то, что крупные институты все чаще оказывались не в состоянии провести свою волю в жизнь» (Штер, 2019: 390). Он же показывает, в частности, что критика в отношении науки как социального института связана с тем, что на многие значимые для жизни людей вопросы она пока не дала ответов. Он цитирует в связи с этим исследователя, по мнению которого «наши исследования не всегда направлены на вопросы, непосредственно касающиеся большинства населения; результаты, о которых договариваются эксперты, не всегда опираются на основания, которые готова принять широкая общественность, а распространяемая информация настолько извращена, что вместо свободной дискуссии и дебатов имеет место непродуктивная перепалка по принципу “кто кого перекричит"» (там же: 428). 


\section{КРИЗИС АОВЕРИЯ И ПАНАЕМИЯ}

Проблема эрозии доверия поднимается исключительно часто в контексте пандемии. Отсутствие «онтологической безопасности» (Э. Гидденс) в контексте эпидемии вызвало к жизни лавину интерпретаций происходящего, к которым прибегают и профессионалы, и не профессионалы. Во многих странах недоверие действиями властей соединялось с недоверием ученым и медикам, особенно в связи с тем, что их мнения по поводу опасности вируса, высказываемые публично, значительно отличались в плане оценки угроз, а зачастую и противоречили друг другу.

Приведем в качестве иллюстрации краткую динамику суждений об опасности коронавируса и необходимых мерах по сдерживанию эпидемии.

1. «Вирус не опаснее простуды и гриппа, небольшая температура и насморк. К лету ослабнет, вирусу трудно размножаться при высокой температуре, надо продержаться три месяца, тогда и снимут ограничения».

2. «Очень опасный вирус, карантин, нельзя гулять в парках, можно только до ближайшего магазина и аптеки, а также выгулять собаку. Нужны маски и перчатки. Аети и молодежь болеют легко и бессимптомно, поэтому все внимание на людей $65+»$.

3. «Второй, третьей и пр. волны не будет. Аальнейшие локдауны не планируются. Ждем вакцину, это спасение. Вакцинированные не будут заражаться. Им можно не носить маски. Надо одноразово привить около 70 процентов людей в стране старше 18 лет, тогда будет коллективный иммунитет и вирусу будет сложно распространяться. Перчатки не нужны. Вакцинированные будут заражаться, но болеть легко».

4. «Аети и молодежь тоже могут тяжело заболеть. Вакцинированные будут заражаться и болеть, в том числе достаточно тяжело, но не будут умирать. Ревакцинация не потребуется, прививка нужна один раз и будет действовать год-два.

5. «Ревакцинация нужна каждые полгода. Ревакцинацию не имеет смысла делать тем же препаратом, что и исходная вакцинация. Ревакцинацию можно и нужно производить тем же или доступным на тот момент препаратом».

Как видно из этого краткого обзора, риски коронавирусной инфекции получали разные оценки на различных этапах разворачивания эпидемии. Аюди повсеместно отреагировали на неопределенность и противоречивость информации о вирусе ковида волной конспирологических представлений. Например, возникали идеи, связывающие появление коронавируса с вышками связи $5 \mathrm{G}$, отрицание существования коронавируса в целом (ковид-диссидентство), проблемы с бесплодием после вакцинации, отрицание необходимости вакцинирования и пр.

Реализация антиковидных мер достаточно грубо разделила мир на две его части: страны, в которых исполняются принимаемые правительствами меры (например, Восточная и Юго-Восточная Азия), и страны, жители которых оказывают сопротивление вводимым ограничениям (западные страны, Россия). В большинстве западных стран уровень доверия властным институтам не находится на высоком уровне, а во многих странах Восточной и Юго-Восточной Азии доверие все еще достаточно высоко.

В 2021 г. компания Edelman опубликовала доклад, в котором оценивает изменения доверия в связи с пандемией коронавируса (Edelman Trust Barometer, 2021: Электронный ресурс). Падение доверия правительственным структурам заметно не только в тех западных странах, где оно и так не было высоким, но также 
в незападных странах. Например, в Китае, согласно оценкам Edelman, отмечается 18-процентное снижение доверия по сравнению с весенними показателями 2020 г. Падение доверия политическим дидерам сопровождается эпидемией дезинформации, а доверие всем видам медиа находится на рекордно низком уровне. Более того, «плохая информационная гигиена», т. е. отсутствие проверки как источников информации, так и ее самой, становится детерминантой нежелания вакцинироваться (там же).

Обратимся к мнению британских исследователей, которые проследили факторы, вносящие вклад в доверие/недоверие жителей своей страны к предпринимаемым правительством в условиях эпидемии мерам (Calnan, Williams, Gabe, 2020: Электронный ресурс).

Авторы исследования определяют доверие через его составные аспекты. Согласно их позиции, доверие предполагает как когнитивную составляющую (основанную на рациональных и инструментальных суждениях), так и аффективное измерение (основанное на отношениях и аффективных связях), создаваемые в результате взаимодействия, эмпатии и идентификации с другими людьми. Аоверие возникает в ситуации, когда у доверяющего есть позитивное ожидание в отношении компетенций и знаний другой стороны (компетентностное доверие), которое позволит той хорошо выполнить свою работу и сделать это с максимальным учетом интересов доверяющей стороны (интенциональное доверие). Аоверие взаимно: публичное доверие институтам необходимо для легитимации принимаемых ими решений, а правительство должно доверять людям, которые эти решения поддержат.

Эрозия доверия, по мнению британских исследователей, наблюдается в нескольких аспектах. Во-первых, доверие британцев правительству достаточно быстро стало снижаться после начала эпидемии. Жители Британии отметили ряд противоречий в его деятельности, которые получили негативную оценку: сомнения в том, что правительство действовало достаточно быстро в самом начале эпидемии, а также в том, что оно следовало научному подходу в разрешении кризиса; недостатки тестирования на коронавирус; предположительные нарушения самими чиновниками правил карантина, которые ими же и были введены. Авторы отмечают, что здесь задействованы два обозначенных ими аспекта доверия, таких как доверие компетентности и доверие тому, что властные институты действительно предприняли все меры в интересах людей.

Во-вторых, доверие цифрам, которыми людей «бомбардировали» ежедневно, и математическим моделям, стоящим за этими цифрами. В связи с избытком информации о числе зараженных и умерших и кривых заражения и спада заболеваемости многие люди превратились в «диванных эпидемиологов», рассуждающих, например, о том, как «сделать кривую заражений более плоской». Авторы ссылаются на исследователя, который назвал происходящее «театром цифр», критикуя такой способ коммуникации правительства с британцами.

B-третьих, доверие людям. Это подразумевает как доверие правительства гражданам своей страны в отношении того, что принятые наверху решения будут исполняться, так и доверие людей друг другу во время эпидемии. Примером служит нежелание людей соблюдать меры социального дистанцирования после первого локдауна (во время которого люди таким мерам в целом следовали). Кроме того, люди должны доверять друг другу и иметь определенную долю ответственности 
перед наиболее уязвимыми с точки зрения әпидемии людьми, к которым также относятся пожилые, что авторы называют альтруистическим доверием. К такому виду доверия также отнесено доверие к волонтерам.

Наконец, важную роль играет доверие технологиям, которое включает в себя разные измерения. В частности, вводимые властями электронные системы отслеживания тех, кто заболел, содержат большой объем информации о людях, в связи с чем возникают вопросы из области доверия: конфиденциальности этих данных и исключения их неправомерного использования (там же).

Обозначенные аспекты доверия, подверженные эрозии, являются общими для многих стран.

Кроме того, в качестве «уроков ковида» датские исследователи предлагают доверять населению в плане предоставления ему полноты информации (Petersen, 2021: Электронный ресурс). Аания относится к числу стран с одним из самых высоких уровней доверия. Несмотря на это обстоятельство, автор приводимой статьи рекомендует прислушаться к датскому опыту и считает его релевантным и для других стран, в том числе с низкими показателями доверия. Его аргументация строится на основании ряда исследований, в которых было установлено, что перед лицом несчастий люди не проявляют избыточных панических настроений. Однако, в противоположность научно обоснованным данным, исходные интенции лидеров ряда западных стран состояли в том, чтобы приуменьшить риски коронавирусной инфекции, дабы не сеять панику. «Когда правительства предполагают, что люди запаникуют, это усиливает пандемию», - отмечает автор (там же). Контрпродуктивно отрицать способность людей рационально оценить то, что происходит. «Правительства, недооценивающие своих людей, фокусируются на том, чего публика не может сделать», в то время как людям нужна понятная информация, чтобы они знали, какие действия предпринимать. Вместо того чтобы предоставлять людям точную информацию о возникающих штаммах коронавируса, преимуществах и рисках вакцинации или о снижении иммунитета через какое-то время после нее, власти прибегают к «туманным заверениям» (там же). Подобный «патерналистский» стиль руководства себя не оправдывает, отмечает исследователь: неопределенность препятствует, например, принятию решения о вакцинировании и снижает доверие к властям и системе здравоохранения. Разорвать порочный круг недоверия или уменьшить взаимное недоверие можно и нужно. Автор предлагает прибегнуть к теории игр, в которых исход последней определяется действиями того, кто ее начинает. Поэтому вывод, к которому приходит исследователь, состоит в том, что только представители власти могут сделать первый шаг, начав доверять людям (там же), запуская тем самым механизм будущего взаимного доверия.

В 2021 г. одной из самых актуальных проблем стало нежелание людей вакцинироваться. Несмотря на различия эпидемических ситуаций в разных странах, мотивация является сходной. К примеру, в Австралии невакцинированные люди не хотят прививаться, обосновывая это следующим образом: «я подожду другую (более надежную. - $В$. . Ф.) вакцину», «ковид - легко протекающая болезнь и не опасен», «я не доверяю вакцинам, поскольку их сделали в спешке», «мой риск инфицирования ковидом низок», «мой друг (родственник) сказал мне не вакцинироваться» (7 reasons ..., 2021: Электронный ресурс).

Американцы, которые не хотят делать прививку против коронавируса, также высказывают ряд тревожащих их соображений в поддержку собственного реше- 
ния. Опрос, проведенный американским исследовательским центром Pew Research, показал, что восемь из десяти невакцинированных выразили согласие со следующими предложенными суждениями: «слишком много давления оказывается на тех, кто не хочет вакцинироваться» $(88 \%)$, «мы пока еще не уверены в том, что нет серьезных рисков здоровью от вакцин против коронавируса» (81\%), «специалисты в области здравоохранения не говорят нам всего, что они сами знают о вакцинах против ковида» (80\%). Кроме того, семь из десяти невакцинированных американцев также солидарны с высказыванием, что «трудно сориентироваться и понять всю информацию о вакцинах против COVID-19» (Funk, Gramlich, 2021: Электронный ресурс).

Мотивы россиян, не желающих вакцинироваться, мало отличаются от жителей других западных стран и в основном также лежат в плоскости недоверия: недоверие властям, недоверие официальной статистике или ее противоречивость, недостатки политической коммуникации, недоверие вакцинам ( «недостаточно готовые»; «побочные эффекты»; некоторые называют в качестве причины неодобрение вакцин другими странами, ввиду чего нельзя путешествовать после российских прививок). Отметим необходимость для власти грамотно выстраивать коммуникацию с людьми: считать их опасения о том, что вакцина сделана слишком быстро, недостаточно апробирована и эффективна, легитимными и заслуживающими убедительных ответов, снимающих многие страхи, риски и слухи.

Значительную часть непрививающихся жителей России, равно как и других западных стран, представляют те, кто сомневается. Сомневающихся общественное мнение зачастую относит в одну группу с активными противниками вакцинирования, хотя исследования показывают, что это не так. Сомневаться - совсем не означает занимать антивакцинаторскую позицию. Сомневаться означает не иметь уверенности, веры в то, что это оптимальный вариант, доверия властям, а также убедительных доказательств в пользу вакцинации (убедительных - т. е. таких, которые люди сочтут обоснованными). Источником сомнений становится, в частности, несовпадение знания собственного опыта или опыта знакомых с официальной линией государственных структур. Аргументы представителей власти зачастую не воспринимаются как убедительные. Отрицание компетентности политиков и медиков может быть определено как еще одна причина нежелания прививаться. Аюди выражают сомнение в наличии в их распоряжении достаточного количества информации для взвешивания рисков в пользу или против вакцинирования и принятия решения. Например, трудно объяснить такие явления, когда некоторые люди находились в одном помещении с зараженными, но не заболели. Такая ситуация бывает на работе, а также дома, когда заболевший еще бессимптомен. Многие люди не понимают, что прививка может дать положительного лично им. То, что привитые также могут заболеть в достаточно тяжелой форме, не добавляет популярности идее вакцинирования.

Отсутствие доверия людей в России к проблемам серьезности коронавируса проистекает и из-за усталости бояться и, как выяснилось в исследованиях, - отсутствия массового страха перед вирусом (Синяков, 2021: Электронный ресурс). Подобная усталость подпитывает традиционный российский фатализм, воплощенный в формуле «если суждено - умру». Кроме того, мы традиционно не относимся к здоровью рационально как к важному для сбережения ресурсу. Такое понимание не заложено в нашей национальной культуре в отличие, например, от ази- 
атских стран, и не является выработанным свойством, соответствующим либерализму и индивидуализму, как в западных странах. Хотя, как мы видим, установки в отношении вакцинации в незначительной степени определяются подобными соображениями, а более зависят от атмосферы доверия.

Кризис доверия власти проявляется и в том, что большее доверие люди оказывают не официальной информации, а словам знакомых (знакомым знакомых и др.), которые легко переболели, не привились и не болеют, не носили маску и не болели и пр. Результатом кризиса институционального доверия становится редукиия доверия на микросочиальный уровень - доверие знакомым, коллегам, родственникам. Цюди не видят оснований не доверять информации от случайных знакомых и даже незнакомых. Не предполагают, что такая информация может быть намеренно или случайно искажена источником информации или в процессе ее передачи по коммуникационным каналам от человека к человеку.

\section{АОВЕРИЕ И ВЗАИМНОСТЬ}

Различия в поведении людей, принимающих решения по поводу своего здоровья, описываются моделью, основанной на взаимодействии пяти факторов (Robson, 2021: Электронный ресурс). Эта модель пригодна для изучения нежелания прививаться от коронавируса:

- «Уверенность» - доверие человека әффективности и безопасности вакцин, системе здравоохранения и лицам, определяющим политику, т. е. принимающим решение об их использовании.

- «Самоуспокоенность»: считает ли человек, что болезнь представляет серьезную опасность для его здоровья.

- «Расчет»: вовлеченность человека в поиск информации для взвешивания рисков и преимуществ вакцинации.

- Ограничения или удобство: степень доступности вакцины для человека.

- Коллективная ответственность: готовность защитить других от инфекции с помощью собственной вакцинации (там же).

Принятие решения является следствием взаимовлияния микро- и макросоциальных факторов. Коллективная ответственность становится одним из наиболее уязвимых компонентов. Ее уязвимость порождается (не)готовностью людей к взаимности определенного типа. Взаимность или реципрокность представляет собой направленность действия человека по отношению к другим людям или социальным структурам и проявляется в отношении людей к ношению масок и вакцинации.

Чтобы прояснить нашу позицию, обратимся к классификации реципрокности, предложенной знаменитым американским антропологом М. Салинзом (Салинз, 1999). Он выделил два ее крайних и промежуточный варианты. Одна из крайних точек реципрокности названа им генерализованной реципрокностью и представляет собой альтруистичность, готовность оказать помощь, щедрость, односторонний поток благ. Салинз характеризует этот вид реципрокности как «полюс социабельности». Ожидание отдачи, ответного действия не проявляется. Обратные обязательства, отмечает Салинз, «не оговариваются ни во временном, ни в количественном, ни в качественном отношениях» (там же: 177).

Генерализованной реципрокности противостоит негативная реципрокность «полюс антисоциабельности (недружественности)». Под ней Салинз понимает по- 
пытку «безнаказанно получить что-либо, ничего не отдавая взамен» (там же). Участники взаимодействия стремятся достичь максимальной выгоды за счет другой стороны, выступая носителями противоположных интересов.

Промежуточной формой выступает сбалансированная реципрокность. По мнению Салинза, ее критерием служит «неприемлемость одностороннего движения». «Стороны вступают во взаимодействие, - отмечает Салинз, - как носители далеких друг от друга экономических и социальных интересов» (там же: 180). При отсутствии соразмерного, эквивалентного ответа отношения прерываются. На наш взгляд, это нейтральная форма взаимности, широко распространенная в современном обществе и характерная не только для безличных и формальных отношений, но также и для ряда межличностных отношений. Она требует от участников социальных отношений равного вклада во взаимодействие.

Проиллюстрируем взаимность на примере ношения масок. Нежелание людей носить маски во время пандемии является одним из симптомов перехода от сбалансированной реципрокности, подразумевающей доверие к другой стороне взаимодействия, к негативной. Причем это осуществляется в отношении не только формальных институтов, но и обычных людей, окружающих нас. Ношение масок связано с физическим неудобством для того, кто надевает (большинство людей отмечает, что в них труднее дышать и пр.), а также с материальными затратами на их постоянную покупку. Аля целей нашего исследования самым важным является другое - то, что маски в меньшей степени защищают того, кто их носит, а в большей степени защищают от того, кто их носит. Носящий маску, в сущности, защищает окружающих. В связи с этим он ожидает от них равновесного возмещения, которое заключается в том, что другие также позаботятся о нем и будут использовать маски. Однако, как мы видим, подобные ожидания редко оправдываются. В массовом порядке и добровольно люди не настроены использовать маски. Во многих развитых странах маски носят в том случае, если за их отсутствие накладываются серьезные санкции материального характера. Носящий маску проявляет в подобных условиях элементы взаимности, находящиеся между генерализованной и сбалансированной реципрокностью, а действия тех, кто ее не носит, могут быть охарактеризованы как негативно реципрокные. Не носящие маску нисколько не ошушают себя стесненными взаимными обязательствами и должными тем, кто ее носит, и не воспринимают свои действия как әгоистичные и антисоциабельные. Ожидания тех, кто стесняет себя ношением масок, не располагают к себе, не находят поддержку и адекватного эквивалентного ответа у тех, кто в большей степени склонен заботиться о своем удобстве и не носить их. При этом негативная реципрокность, на наш взгляд, не является однородной. Она может представлять собой континуум действий: от слабой формы - не воспринял это как действие, требующее соразмерного ответа, не подумал об этом, до сильной я не хочу, мне не удобно, и маска меня не защищает.

Фактически, на наш взгляд, можно говорить о позитивно, нейтрально или негативно окрашенных типах взаимности. В условиях пандемии общий контекст социального взаимодействия еще сильнее смещается в сторону обобщенного недоверия, а ожидания - в сторону негативной взаимности или невзаимности. Конструируются множественные смыслы невзаимности и недоверия. Вместе с тем получают распространение новые практики позитивной взаимности - альтруистическое поведение врачей и волонтеров и пр. В микросоциальных контекстах, включающих 
близких людей и знакомых, сохраняются доверие и позитивно или нейтрально окрашенная взаимность.

\section{ЗАКАЮЧЕНИЕ}

Сделаем вывод о том, что доверие (равно как и недоверие) является результатом сочиального конструирования. Следовательно, чтобы запустить механизм взаимного доверия, нужна политика доверия, первые шаги в которой, и в этом мы согласны с упомянутыми выше датскими авторами, следует предпринимать властным структурам. Это, безусловно, займет определенное время и потребует серьезных усилий, но мы полагаем, что люди с радостью вернулись бы к определению ситуации как заслуживающей доверия, поскольку в этом и заключается, по существу, естественная среда функционирования сложного современного общества. Более того, на наш взгляд, в связи с кризисом доверия люди испытывают неудовлетворенную потребность доверять. Стремление $к$ конструированию саморегулируемьх доверительных контекстов прослеживается во многих действиях людей, в том числе в цифровом пространстве. Здесь возникают, например, такие его продукты, как цифровые деньги и цифровые сертификаты, гарантирующие оригинальность предметов искусства и пр., которые своим существованием обязаны представлению о новых цифровых практиках как заслуживающих доверия. Необходимость и привлекательность доверия с неизбежностью устремлены к своей реализации.

\section{СПИСОК АИТЕРАТУРЫ}

Салинз, М. (1999) Экономика каменного века / пер. с англ. О. Ю. Артемовой и др. М. : ОГИ. 296 с.

Синяков, А. (2021) В России провалился план по вакцинации населения от коронавируса. Почему это произошло? [Электронный ресурс]// Сноб. URL: https://snob.ru/entry/237880/ (дата обращения: 30.09.2021).

Федотова, В. Г. (2020) Жизнь в условиях коронавируса // Знание. Понимание. Умение. № 3. C. 90-99. DOI:10.17805/zpu.2020.3.7

Штер, Н. (2019) Информация, власть и знание. СПб. : Алетейя. 571 с.

Штомпка, П. (2012) Аоверие - основа общества / пер. с пол. Н. В. Морозовой. М. : Аоroc. $440 \mathrm{c}$.

Шюц, А. (2004) Возвращающийся домой// Избранное: Мир, светящийся смыслом/ пер. с нем. и англ. В. Г. Николаева, С. В. Ромашко, Н. М. Смирновой ; общ. и науч. ред., послесл. Н. М. Смирновой. М. : Российская политическая энциклопедия (РОССПЭН). 1056 с. С. 550-556.

7 reasons people don't get COVID-19 vaccinations, and why you should - right now [Электронный ресурс] // Healthdirect. URL: https://www.healthdirect.gov.au/blog/7-reasons-people-dont-get-covid-19-vaccinations (дата обращения: 22.08.2021).

Bailenson, Jeremy N. (2021) Nonverbal Overload: A Theoretical Argument for the Causes of Zoom Fatigue // Technology, Mind and Behavior. Vol. 2. Iss. 1. P. 1-6. DOI: 10.1037/tmb0000030

Calnan, M., Williams, S. J., and Gabe J. (2020) Uncertain Times: Trust Matters During The Pandemic [Электронный ресурс] // Discover society. URL: https://archive.discoversociety.org/2020/06/01/uncertain-times-trust-matters-during-the-pandemic/ (дата обращения: 01.09.2021).

Edelman Trust Barometer 2020 [Электронный pecypc] // Edelman. URL: https://www.edelman.com/trust/2020-trust-barometer (дата обращения: 03.09.2021).

Edelman Trust Barometer 2021 [Электронный pecypc] // Edelman. URL: https://www.edelman.com/sites/g/files/aatuss191/files/2021-03/2021\%20Edelman\%20Trust\%20Barometer.pdf (дата обращения: 28.08.2021). 
Funk, C., Gramlich, J. (2021) 10 facts about Americans and coronavirus vaccines [Электронный ресурс] // Pew Research Center. URL: https://www.pewresearch.org/fact-tank/2021/ 09/20/10-facts-about-americans-and-coronavirus-vaccines/ (дата обращения: 22.09.2021).

Petersen, M. B. (2021) COVID lesson: trust the public with hard truths // Nature. № 598 (7880). P. 237 [Электронный ресурс] // Nature. URL: https://www.nature.com/articles/ d41586-021-02758-2? error=cookies_not_supported\&code $=$ f3c45738-5e 47-4ea 2-9ed0e97deec47488 (дата обращения: 28.08.2021). DOI: 10.1038/d41586-021-02758-2

Robson, D. Why some people don't want a Covid-19 vaccine [Электронный ресурс] // ВBC. URL: https://www.bbc.com/future/article/20210720-the-complexities-of-vaccine-hesitancy (дата обращения: 22.08.2021).

Аата поступления: 10.10.2021 2.

\section{COVID-19 PANDEMIC IN 2021: TRUST ISSUES \\ V. G. FEDOTOVA \\ RAS INSTITUTE OF PHILOSOPHY}

The article examines the impact of the coronavirus pandemic on everyday life. The author turns to the social phenomenology of A. Sch?tz and his concept of the home. Changed by the pandemic and its constraints, home is challenging our understanding of it. It begins to look like someone else's home, we become strangers to it. Changes in one's home put us in the position of people devoid of some subjectivity.

The pandemic finds many societies in a crisis of institutional trust that manifested itself long before. Areas of trust most susceptible to erosion in a pandemic are shown. Trust is redistributed: it is reduced from the level of macro-structures to micro-social interactions. One of the manifestations of the issue of trust is the reluctance of people in many countries of the world to get vaccinated. The motivation underlying the reluctance and postponement of vaccination contains both universally used excuses and some arguments reflecting Russian specifics.

Reciprocity, which is the orientation of a person's action towards other people or social structures, manifests itself, in particular, in people's attitudes to new practices of using masks and vaccination. The issue of trust and reciprocity is reflected in collective responsibility - willingness to protect others from the infection by wearing masks and getting vaccinated. The level of collective responsibility in many countries is not high.

With a crisis of trust, people experience an unmet need to trust. The author sees the solution to the problem of trust in the need for its social construction with the help of trust policy.

Keywords: coronavirus; pandemic; epidemiological transition; home; trust; crisis of trust; wearing masks; vaccination; reciprocity

\section{REFERENCES}

Salinz, M. (1999) Stone Age Economics / transl. from English by O. Iu. Artemova et al. Moscow, OGI. 296 p. (In Russ.).

Sinjakov, A. V Rossii provalilsja plan po vakcinacii naselenija ot koronavirusa. Pochemu jeto proizoshlo? Snob [online] Available at: https://snob.ru/entry/237880/ (accessed: 30.09.2021). (In Russ.).

Stehr, N. (2019) Information, Power, and Democracy: Liberty is a Daughter of Knowledge. Saint-Petersburg, Aleteija. 571 p. (In Russ.).

Stompka, P. (2012) Doverie - osnova obshbestva / transl. from Polish by N. V. Morozova. Moscow, Logos. 440 p. (In Russ.).

Schuetz, A. (2004) The Homecomer. In: Schuetz, A. Izbrannoe: Mir, svetjashbijsja smyslom. Moscow, Russian Political Encyclopedia. 1056 p. Pp. 550-556. (In Russ.).

7 reasons people don't get COVID-19 vaccinations, and why you should - right now. Healthdirect [online] Available at: https://www.healthdirect.gov.au/blog/7-reasons-peopledont-get-covid-19-vaccinations (accessed: 22.08.2021). 
Bailenson, Jeremy N. (2021) Nonverbal Overload: A Theoretical Argument for the Causes of Zoom Fatigue. Technology, Mind and Bebavior, vol. 2, iss. 1, pp. 1-6. DOI: 10.1037/tmb0000030

Calnan, M., Williams, S. J. and Gabe J. Uncertain Times: Trust Matters During The Pandemic. Discover society [online] Available at: https://archive.discoversociety.org/2020/06/01/uncertain-times-trust-matters-during-the-pandemic/ (accessed: 01.09.2021).

Edelman Trust Barometer 2020. Edelman [online] Available at: https://www.edelman.com/ trust/2020-trust-barometer (accessed: 03.09.2021).

Edelman Trust Barometer 2021. Edelman [online]. Available at: https://www.edelman. com/sites/g/files/aatuss191/files/2021-03/2021\%20Edelman\%20Trust\%20Barometer.pdf (accessed: 28.08.2021).

Funk, C., Gramlich, J. 10 facts about Americans and coronavirus vaccines. Pew Research Center [online] Available at: https://www.pewresearch.org/fact-tank/2021/09/20/10-factsabout-americans-and-coronavirus-vaccines/ (accessed: 22.09.2021).

Petersen, M. B. (2021) COVID lesson: trust the public with hard truths. Nature [online] Available at: https://www.nature.com/articles/d41586-021-02758-2?error=cookies_not_supported $\&$ code $=f 3 c 45738-5$ e47-4ea2-9ed0-e97deec47488 DOI: $10.1038 / \mathrm{d} 41586-02 \overline{1}-02 \overline{7} 58-2$ (accessed: 28.08.2021).

Robson, D. Why some people don't want a Covid-19 vaccine. BBC [online] Available at: https://www.bbc.com/future/article/20210720-the-complexities-of-vaccine-hesitancy (accessed: 22.08.2021).

Submission date: 10.10 .2021$.

Федотова Валентина Гавриловна - доктор философских наук, профессор, главный научный сотрудник сектора социальной философии, руководитель научного семинара «Социальная философия и развитие гражданского общества в России» Института философии РАН. Адрес: 109240, Россия, г. Москва, ул. Гончарная 12, стр. 1. Тел.: +7 (495) 697-98-93. Эл. aspec: val_fedotova@mail.ru

Fedotova Valentina Gavrilovna, Doctor of Philosophy, Professor, Principal Researcher, Sector of Social Philosophy, Head, Research Seminar "Social Philosophy and the Development of Civil Society in Russia”, Institute of Philosophy, Russian Academy of Science. Postal address: 12, Bldg. 1, Goncharnaya St., Moscow, Russian Federation, 109240. Tel.: +7 (495) 697-98-93. Email: val_fedotova@mail.ru 